\title{
Rethinking the Role of Languages in the US: Toward a More Diverse Cultural Identity
}

\author{
Kathleen Stein-Smith \\ Fairleigh Dickinson University, Metropolitan Campus, USA
}

\begin{abstract}
This article examines the English-only post-colonial narrative that has driven the development of US cultural memory and cultural identity does not sufficiently allow for the presence of other languages and cultures that form part of our diverse cultural identity -- past, present, and future. It finds that the current US foreign language deficit, including both lack of necessary foreign language skills among Americans and lack of motivation among Americans -- believing that English is the global lingua franca -- to learn other languages, impacts national and economic security as well as our communities and our society. The author concludes that the resurgence of Spanish, French, and other languages as our languages, rather than foreign languages, empowers us all. Access to foreign language learning from the earliest grade levels for all interested students will not only impact our economic and national security, but will create a new, and more diverse and sustainable "English plus" American identity for generations to come.
\end{abstract}

Index Terms—foreign language learning, bilingualism, multilingualism, immersion

\section{INTRODUCTION}

The importance of foreign language learning for American students has long been a topic of discussion among scholars, and research reports and government hearings have added to the conversation on the scope and impact of the lack of foreign language skills on Americans.

Scholars have long discussed the importance of foreign languages for American students (Kettelkamp, 1940; Pei, 1956; Huebener, 1961; Simon, 1980; MLA, 2007; AMACAD, 2017), and a series of research reports, and even government hearings(NAFSA, 2003; CED, 2006; O'Connell \& Norwood, 2007; Language Flagship, 2009; GAO, 2010; US Senate, 2012; New American Economy, 2017), have examined the impact of this foreign language deficit on our economics and national security.

In the global era, foreign language skills and knowledge of other cultures are more necessary than ever, as multilingualism is yet another advantage in our role as global citizens, in addition to the cognitive, cultural, and career advantages long associated with foreign language skills.

The disconnection between languages spoken and language learning in the US is evident. While more than $60 \mathrm{M}$, or over 20\%, of the US population speaks a language other than English in the home, fewer than $20 \%$ of K-12 students, and only $7.5 \%$ of college and university students are learning another language (Ryan, 2013; Grosjean, 2018; American Councils, 2017; MLA, 2018).

The reasons for this "legendary" (Stearns, 2009) reluctance to learn other languages have included the role of English as a global lingua franca, but the challenges faced by those who work to increase interest in foreign language learning in the US point to a deeper reason for resistance to language learning - our monolingual collective memory and collective cultural identity.

A more cosmopolitan, and at the same time, more authentic, collective memory and cultural identity could empower us to embrace both the local and the global aspects of other cultures (Gunesch, 2004, 2013), developing more interest in other languages and becoming better language learners.

\section{The Melting Pot Metaphor and Our Monolingual Collective Memory and Collective Cultural IDENTITY}

Memory plays an important role in the transmission of personal and collective cultural identity, but memory may not always be accurate and/or complete - for individuals and for groups. Autobiographical memory, or what we believe ourselves to be, may be incomplete or inaccurate. Even what we believe to be true memories are sometimes at least partially reconstructed, as we try to create meaning from incomplete data (Mazzoni, 2018).

What we believe to be a monolingual cultural identity may be the result of the information that has been transmitted to us, and this information may not always have been complete and may not always have included the many stories that make up our complex history and culture.

The collective memory and the resulting collective cultural identity of many in the US are largely based on a traditional narrative of British colonies, later independent, yet retaining the English language and many British-oriented traditions, and many Americans are even ardent anglophiles. Popular examples of this identification with British 
tradition yet today would include the number of Americans who traveled to Britain to see the royal wedding of Will and Kate, or the 30M who watched the wedding of Prince Harry and Megan Markle.

Even though we may be aware that our American culture is one of many stories, many of us may still assume that English is the official language, and relatively few are even aware that the United States does not have an official language. Even fewer may be aware that bilingual education has always existed in the US, since the colonial era (Goldenberg \& Wagner, 2015).

Other languages flourished to some extent in the early years of our history in many parts of the US, but during the $20^{\text {th }}$ century, historic language communities dwindled in number, with the US losing part of its linguistic identity and tradition. There is even a linguistic urban myth, the Muhlenberg legend, about the possibility of German becoming the official language of the young nation.

The melting pot metaphor, routinely used to describe American culture, had become increasingly English only, and the importance of French, Spanish, and many other languages moved to the periphery of the public conversation and of the US media.

A more accurate collective memory would include the presence of others throughout our history, and across what is now the US, including the fact that the many French and Spanish place names across the country are clear indicators of other presences in what is now the United States, and that among the top 15 surnames in the US, 6 are Hispanic (Census, 2016). Place names across the country, including Bismarck, Stockholm, Carlstadt, and Swedesboro are just a few of the many indicating the diversity of our collective heritage and history.

\section{LANGuAge And OuR Personal And Collective Cultural Identity}

The significance of language, as both a means of communication and transmission of culture, as well as a symbol of belonging, in both our personal and collective cultural identity, should not be under-estimated.

However, in addition to the significance of language, it is important to consider how best to sustain and foster use of other languages as part of our personal lives, in our society, and as global citizens. Important issues to consider are how to develop awareness of the different languages and cultures that have played, and continue to play, a role in the US, and how to create and sustain interest in language learning. In addition, it is important to consider the role of language, not only in terms of communication and of relationships with others, but also as part of a larger system, or environment, in which the whole person lives and functions.

Another element to consider is the continued ability to read news and literature and to understand film and other media that not only are in another language, but that also generally represent another worldview. Americans, confined to the English language space, miss out on the adventure of other perspectives.

In addition to its use as a means of communication, language also plays a symbolic role in establishing a sense of community, and loss of the mother tongue, or community language, can have an adverse effect on self-esteem. It is also the means of expressing this culture through literature, vocal music, etc. This is yet another reason why heritage language education is so important. It is also the means of conveying, preserving, and transmitting the culture, or cultural continuity.

Languages also express things differently, depending on concepts and tangible objects that may exist in particular cultures, if at all, to varying degrees. The formal versus informal forms of address expressed by vous, Usted, Sie, Lei, etc., versus $t u, d u$, etc., are examples of relationship concepts either more important in particular cultures than in others, or expressed more specifically in certain languages and cultures than in others.

Languages in contact, either in the community, or within a particular family or individual, offer a bridge and an intermediary between cultures and an opportunity for the development of a more complex cultural identity resulting from an ongoing conversation, or dialogue of sorts, among the languages present. Languages are also linked with different decision-making and problem-solving styles.

By choosing to remain monolingual, we miss out, not only on the enjoyment of communicating and interacting with others in their language, but we also miss out on opportunities for self-actualization. If our personal cultural identity is viewed as many elements that work together as part of one system, the addition - or suppression - of a language impacts the whole person.

\section{TOWARD A New Multilingual AND Diverse CUltural IDENTITY}

If a new multilingual and diverse cultural identity is to be developed, a paradigm shift in the collective memory and cultural identity needs to occur, and this change needs to occur in our communities and in our schools, and through print, online, and social media. Language advocacy needs to be strategic, and to be informed by theory and best practices in change management, social marketing, the psychology of influence and persuasion, disruptive innovation, and even blue ocean theory, as well as other theories and best practices, in order to advocate for languages to be part of education for all from the earliest ages. In addition to this campaign for languages, the use and learning of other languages need to be fostered and encouraged in our communities, schools, and in the workplace.

However, in a globalized world, the creation of a new cultural identity transcends its historical roots and embraces our future as global citizens, with a cosmopolitan and multilingual identity able to envision multiple worldviews. 
The process of developing a broader cultural identity has been described and can be envisioned in three stages. During the first stage, cultural identity is "unexamined", not part of our day-to-day thoughts. At a second stage, prompted by a personal or educational experience, often during adolescence, an individual may begin to explore their personal heritage. At a third stage, the individual will have developed understanding and acceptance of a broader, more complex version of their cultural identity (Phinney \& Rotheram, 1987; Phinney, 1989). A parallel process at the national or regional level could be envisioned as having three very similar stages.

Many of us are relatively unaware even of our own individual heritage, absorbing the monolingual cultural identity of anglophone American through our communities, schools, and media. This unexamined cultural identity would be the norm among children, but also exists in many adults. A search for one's personal cultural identity could be the result of a personal or educational experience making the student or adult more interested in digging deeper into an area that had previously not been given serious thought, and would typically involve exploring, finding out, and learning more about one's heritage. The ideal end result of this process could be imagined as the development of understanding and acceptance of one's heritage as part of one's personal cultural identity.

Overcoming language-resistant behavior among Americans calls for discussion of and learning about other languages and cultures from the earliest grade levels, as well as discussion of the contribution of other cultures to our American experience. Two levels of change -- within individual students, and within the general narrative of our communities, schools, and media -- are needed in order to effect a paradigm shift in attitude toward other languages and toward multilingualism.

The issue becomes one of change management -- how best to work toward a change in how we -- as individuals, and collectively, as Americans, envision our collective memory and our collective cultural identity.

As a result, it is possible to adapt the best theories and practice in change management, social marketing, cause marketing, disruptive innovation, blue ocean strategy, and more to drive a new conversation on a new, more complex, cultural memory and cultural identity reflecting our diverse heritage and history.

Kotter's 8-step theory of change management begins with establishing "a sense of urgency," which is of critical importance in driving a public conversation of such magnitude. It is essential that including all Americans -- past, present, and future, in our collective memory and cultural identity, become a priority. It is indeed, urgent, in both our increasingly multilingual and multicultural society, and in the globalized world and workplace, that we develop the necessary language skills and cultural knowledge.

Because development of a complex and diverse cultural identity reflecting our history and our society is of the utmost social benefit, social marketing -- employing strategies and tactics of business marketing for the social good, and cause marketing -- developing partnerships based on corporate social responsibility, including those in business and industry, to broaden support would also be used to good effect.

The creation of a more diverse sustainable cultural memory and identity would also be an example of disruptive innovation. Not only would a more inclusive cultural identity disrupt the current narrative, it would also disrupt education, specifically foreign language education, as we know it. Awareness, interest, and engagement with other cultures would begin early, across disciplines, ideally in an immersive intercultural environment.

Blue ocean strategy, an approach centered on developing interest among new markets, or "blue oceans," as opposed to the red oceans of cutthroat competition, would apply to the challenge of fostering interest in other languages and cultures among individuals, communities, and organizations hitherto unaware and uninterested in them.

Foreign language educators, advocates, and stakeholders should view the current moment, with bilingualism on the rise (Grosjean, 2018), along with awareness of the importance of foreign languages here at home and in the globalized world as a tipping point, where our individual actions can, indeed, "make a big difference" (Gladwell, 2002).

\section{Multilingualism and a More Cosmopolitan Cultural IDEnTity}

"Language is a critical instrument that shapes one's view of the world. Understanding the meaning of the words other people use yields perhaps the most insight into cultural differences. Language both describes and limits what we see" (Adams \& Carfagna, 2006).

The phrase "at home in the world" has often been used to describe a cosmopolitan, or global citizen (Brennan, 1997; Olson et al, 2007), and language is an important part of this ability to understand, appreciate, and effectively navigate other cultures.

Just as language skills can help us to more fully develop and understand our personal cultural identity, our heritage, and our national cultural identity as Americans, they can also help us to develop a more cosmopolitan cultural identity as the global and the local become more interconnected.

The ability to understand information from the perspective of another culture through print, online, and social media, and to communicate directly with others without translation or other language barrier, is a significant factor in developing an international and global citizenship mindset and in being able to play an active role as global citizens in effectively addressing complex global issues.

As knowledge of other languages offers personal and professional benefits, parents and families can consider encouraging use of their mother tongue or heritage language in the home so that their children, grandchildren, and 
future generations will enjoy not only the cognitive and professional advantages of bilingualism, but also so that they will continue to be able to fully participate in both cultures and understand and appreciate their identity and heritage.

Research confirms that bilingualism does not confuse children, but that - as language learning is a long process children learning and using more than one language may take longer to reach certain milestones. In addition, both the quality and quantity of input in both languages plays an important role, and bilinguals may, in fact, have different skill levels in each language, depending both on input received and their use of each language (Hoff \& Core, 2015).

(Gunesch, 2004, 2006; \& Ros i Sole, 2013) build on the fact that - far from being a detriment - multilingualism empowers us as global citizens to develop cosmopolitan cultural identities, perhaps even developing multiple identities, as our mindset changes when we change languages.

An example of the role of multilingualism in global citizenship is the Many Languages One World Essay Contest and Global Youth Forum (MLOW), in which college and university students from around the world submit essays written in a learned second language, which is also one of the 6 official languages of the United Nations. Winners, generally 10 for each of the 6 languages, spend a week on a US campus and have the opportunity to present in the General Assembly Hall of the UN, in the language of their winning essay, generally on the sustainable development goals, the UN global development agenda 2015-2030. In addition to the use of a learned second language by these multilingual students, the teamwork and camaraderie displayed by these transnational teams as they developed their group presentations, as well as the lasting friendships formed across cultures, are inspirational.

Ensuring that all our children - from the earliest grades, as well as interested adults, have the opportunity to learn additional languages, will empower us as global citizens, transcending a local, monolingual paradigm to develop a truly global mindset and vision, in a world where - rather than having one lingua franca, generally English, there is a "multilingual franca" (Janssens \& Steyaert, 2014).

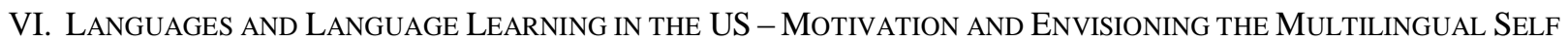

Motivation is considered key to language learning success, and a trait generally shared by successful language learners (Mackey, 2014; Dornyei, 1998; Ramage, 1990; Gardner \& Lambert, 1972). Many Americans are not motivated to learn another language, and do not even see any reason to learn another language because of our monolingual anglophone collective memory and cultural identity, and our mistaken belief that English is the global lingua franca. In addition, US students are often not required to study another language, and many do not even have access to foreign language learning and the opportunity to learn another language.

As the collective memory and collective cultural identity in the US are predominantly monolingual and anglophone, many Americans cannot and do not envision themselves speaking another language fluently or even holding a conversation in another language

This ability to envision oneself fluent in another language is sometimes referred to as the "L2 motivational self," and a lack of ability to envision oneself as a successful language learner may actually play a significant role in our difficulty in learning another language and is related to motivation (Mackey, 2014).

While some 60M speak a language other than English in the home, relatively few English-speaking Americans, as few as one in four, are able to hold a conversation in another language (Ryan, 2013; McComb, 2001). Most monolingual English-speaking Americans may not even envision, or be able to envision, themselves conversing in another language.

In addition to the tendency not to envision ourselves as speaking other languages and lack of motivation, reasons for this disconnect between languages spoken and language learning in the US include the fact that fewer than $20 \%$ of K-12 students study another language and that only $7.5 \%$ of college and university students are enrolled in a course in a language other than English (American Councils, 2017; MLA, 2018). Compared to Europe, where virtually all students study at least one additional language beginning at an early age, the relatively small percentage of US students learning another language is noteworthy (Devlin, 2015, 2018). In addition, it is important to remember that a relatively small percentage of US students is even afforded this opportunity.

Another reason for the disconnection between languages spoken and language learning in the US is that many US students are not required to study another language. Foreign language requirements vary from state to state, and even where requirements exist, they are often minimal, or can be selected cafeteria-style among several non-language options (ECS, 2007). A conversation with a local school administrator or decision-maker may often yield general and noncommittal responses. Even students enrolled in foreign language study often opt for an elementary course for a relatively easy A and abandon language study at the earliest opportunity, or undergraduates register for an elementary foreign language course even after several years of study in high school. College foreign language requirements for entrance and for graduation vary as well (MLA, 2012).

The challenge is to determine the cause, or source, of this language-resistant behavior in order to effectively address it. While languages are spoken by large numbers in the US, and are increasingly important in the workplace, the fact remains that many Americans never even begin study of another language.

This paradoxical pattern of language-avoidance behavior is taking place outside the classroom, before actual foreign language study, so it is not a question of curriculum or of the individual teacher, and the reason often given that English is enough, and that if one speaks English, the global lingua franca, no additional languages are needed. However, while 
English is widely studied and learned around the world, three-quarters of the world's population does not speak English (British Council, 2013). In addition, in many US communities, knowledge of a second language is an advantage. From a workplace perspective, it is important to note that many job openings of all types require foreign language skills and cultural knowledge (New American Economy, 2017).

The decision to learn another language may be driven by a variety of reasons, and motivation is considered the major factor in successful language learning outcome. The strategies used by the language learner, and by those who support the learning process in the classroom, at home, at work, and in the community also impact potential success.

Current research on motivation in second language learning, which is generally considered to have begun in officially bilingual Canada with the work of Gardner and Lambert, is sometimes referred to as being from the social psychological or the cognitive period. (Gardner \& Lambert, 1972) examine language learning from a social perspective, driven most effectively by integrative motivation, a desire to communicate and interact with the target culture. Cognitive research, often associated with the research of Dornyei and Ushioda, examines L2 learning through learning behaviors during different stages of the language learning process.

In terms of language learning as a function of our interest in other languages and cultures as part of our individual personal cultural identity and our collective cultural identity as Americans, the socio-cultural model is the more applicable in building and sustaining motivation. Cognitive theories of motivation are useful to both the learner and the classroom teacher in empowering students to persevere during the inevitable challenges of learning another language.

Learning a new language involves the whole person and transcends both disciplinary boundaries and the confines of the classroom, and language is part of everything we do Daily life is infused with language, so language learning needs to be part of everything we do throughout the day. This holistic aspect of language learning is one of the reasons that family and community support are so important in the success of immersion programs. However, without sufficient motivation, that level of dedication and concentration is difficult to achieve and to maintain.

As Americans are such reluctant language learners, it is interesting to examine not only the reasons for this reluctance, but also strategies to increase both the number of Americans learning another language and their level of success. The answer, at least in part, may lie in the fact that language is generally considered part of one's personal cultural identity, based on memories of family, friends, and experiences, and this memory and identity vary from individual to individual, and may include - or not - more than one language. Perhaps the reason for our reluctance to learn another language lies, at least in part, in our collective cultural identity.

However, our cultural identity, and the memories that build, support, and sustain it, is also collective, and our tenacious monolingualism may result from the fact that our collective memory is monolingual and anglophone.

Memory plays a significant role in learning a language. Without memory, we would not be able to sequentially build linguistic skills, remember vocabulary, etc. Memory also plays a significant role in the development and understanding of our identity, and in our ability to form and maintain relationships. Our collective memory, transmitted through generations by parents, communities, schools, and the media, is at the heart of our cultural identity, both as individuals and as members of our local, regional, and national communities.

Americans are known to be reluctant language learners, with relatively few Americans fluent in one or more additional languages, and a reason often given by way of explanation is that many believe that English is the global lingua franca and that there is little reason to learn another language. While English is widely studied and spoken, 75\% of the world population does not speak English. While a case could be made for a special status for French, along with Spanish and other languages, as US historical and heritage languages, a serious challenge to language learning is the anglophone narrative of our history and culture - in essence, our collective memory. This collective memory, at the core of the transmission of our cultural identity, is overwhelmingly anglophone, and young Americans learn about the British colonies and Shakespeare, rather than learning about the historical and enduring importance of France and other cultures in our past, present, and future.

However, memory - whether individual or collective - is not always accurate or complete, and transmission of our collective memory is generational, taking place through the family and community, schools, and the media, and memory can be updated and completed by including other voices to develop a more nuanced narrative and more authentic narrative.

\section{FRENCH -- AN EXAMPLE OF AN AMERICAN LANGUAGE}

One example of this is the lack of general knowledge on the French presence in the US, and the same could be said for other languages and cultures. In a typical K-12 education, American students learn relatively little about the historic French presence in North America, about the impact of the ideas of the French Enlightenment on our own American Revolution, and the significant presence of the French language today through millions of French language speakers in the US, and through the French ancestry and heritage of over 10M Americans. The 2018 acceptance of Louisiana into the Organisation internationale de la Francophonie may have even been a surprise to many Americans, unaware of the scope of the French presence in Louisiana, as well as in New England, both historically and at the present time, and of its current presence in South Florida and New York City.

To follow this particular example, from the earliest grades, the contributions of France, Franco-Americans, Francophone cultures, both locally and globally, need to be part of the curriculum. This is especially facilitated when 
students have the opportunity to begin continued foreign language study at an early age, as cultural skills and knowledge are generally infused into the foreign language learning process, whether through traditional foreign language learning or through an immersion program.

In order to support the growth of opportunity for foreign language study, a conversation on the role and importance of multilingualism in a globalized world needs to be developed and expanded to include parents, communities, and the general public, in addition to scholars and educators.

In addition to books for school-aged children, the media also needs to better reflect the voices of French-speaking communities, as well as those where French is in danger of being lost or forgotten, reaching out with a variety of offerings to respond to different interests.

While French culture is amazingly present throughout the US, attention also needs to be paid to the language itself, developing proficiency and fluency through heritage language learning, and developing a new generation of Frenchspeakers through FLES and immersion programs.

A similar case could be made for Spanish and other languages and cultures within the US.

Once a decision is made to opt for a broader narrative of our American cultural identity, it is important to consider the significance of language in our personal and collective cultural identity and the factors that foster language learning success.

The motivation-driven decision to learn another language is only the first step. As language is part of our personal cultural identity, and plays an important role in communication, learning, and self-expression, just as the elements of our personal cultural identity are related, so too are our languages, and the ways of learning language are related to everything else. These include ecological and holistic theories of language learning, as well as experiential learning. Learning another language is an example of transformative learning, as it impacts and transforms the whole person.

For these reasons, language learning that builds on the connectedness of language to all areas of life, with authentic situations and language, along with experiential learning, are generally the most effective. This is where the effectiveness of immersion programs, especially dual-language immersion, is highlighted.

\section{From the Monolingual to the Multilingual AmericAn - EnCouraging Language LeARning AND the USE OF LANGUAGES}

In order to encourage the development of language skills, it is necessary to encourage language learning from the earliest age, and at any age, as well as the use of languages at home, at school, in the workplace, and in the media and public life.

Cultural Intelligence (CQ) is a theory built on 4 steps toward developing the ability to effectively navigate another culture, and while CQ is generally considered part of the world of international business and management, its 4 steps CQ drive; CQ knowledge; CQ strategy; and CQ action greatly resemble the steps needed to sustain or revive language learning within our society (Livermore, 2016).

The concept of translanguaging, with involves the inclusion of all the learner's linguistic skills and knowledge, rather than limiting the student to the use of only one language, is an example of the interrelatedness or connectedness of everything, and a bilingual is not "two monolinguals" (Grosjean, 2018).

Encouraging use of more than one language in the home requires a long-term family commitment from earliest childhood through adolescence and young adulthood, with different challenges during each developmental stage requiring a variety of strategies by parents and other caregivers in order to encourage and support bilingualism at home.

Tokuhama-Espinosa (2008) includes aptitude, timing, motivation, strategy, consistency, and opportunity among important factors in raising multilingual children.

Parents and communities wishing to encourage the use of their home language may also want to consider the establishment of a language program in the local public schools. These may be heritage language programs or bilingual programs. The model of bilingual program likely to lead to sustainable bilingualism by developing skills in both the home language and the school language is two-way (TWI) or dual-language immersion (DLI). Heritage language programs are intended to support language learning among learners who have a connection with another language and culture.

"Dual-language education is a universal good that ought to be developed everywhere, as it can positively transform a child, a family, a school, a community, or even a nation" (Jaumont, 2017).

Circling back to the importance of language in our personal and collective cultural identity, teaching and learning environments that engage the whole person, notably immersion programs, would be indicated.

In addition, building on the power of integrative motivation in language learning, both holistic approaches and ecological approaches, which consider language to be part of the ecology, or environmental system, of person or of a community, would be indicated.

\section{CONCLUSIONS}


The problem is that our current cultural identity model is monolingual. Therefore, other languages lack appeal, and many Americans lack the motivation to learn another language. If we can develop a cultural identity more reflective of our diverse society, foreign language learning has a greater possibility of appealing to a larger number of students.

The challenge is to change our collective cultural identity so that students can envision being of, or interested in, another culture -- and by extension, in learning another language.

If our collective memory and cultural identity remain resolutely monolingual, even the best efforts of our foreign language educators, stakeholders, and supporters will face virtually insurmountable odds.

In order to effect the needed paradigm shift in attitudes toward other languages, a re-thinking of our collective memory and cultural identity is an essential first step, to be followed by its representation in the classroom through authentic learning situations, and an early start to foreign languages and to learning about other cultures.

Building foreign language skills in the United States involves changing how we think about ourselves, both at the very deepest, most personal level, and as a society, and re-imagining our personal and collective cultural identity as one with many stories. It is about developing a more flexible and inclusive personal cultural identity -- with room for our heritage, our aspirations, and our role as global citizens. This new personal cultural identity, one that we create and build ourselves, is no longer static and one dimensional, but rather it is dynamic and multidimensional, expanding as we meet new ideas, new situations, and develop a new and evolving idea of our own selves, with multiple personal cultural identities, not mutually exclusive, coexisting and complementing each other.

This new and re-imagined cultural identity and memory can be reflected and supported in the classroom by an early start to foreign language learning and to learning about other cultures, where L1 and L2 are seen in relationship to each other and to a broader vision of community and citizenship, and by fostering bilingualism through immersion (Jaumont, 2017). Immersion offers the best learning environment for this to occur, and partnerships between language stakeholders in education, business, government, and the community are essential.

Multiple languages have always co-existed in what is now the US, and there is actually a strong American historical tradition of bilingual education, lost in the early $20^{\text {th }}$ century, and re-imagined beginning in the 1960 s (Goldenberg $\&$ Wagner, 2015). By embracing immersion education, we are actually returning to a traditional vision of American cultural identity.

As Appiah (2006) wrote, "boundaries can be delightful, or just vexing: what they mainly are, though, is inevitable."

\section{REFERENCES}

[1] Adams, M. \& Carfagna, A. (2006). Coming of Age in a Globalized World: The Next Generation. Bloomfield, CT: Kumarian.

[2] American Academy of Arts and Sciences (2017). America's Languages: Investing in Language Education for the 21st Century. https://www.amacad.org/content/publications/publication.aspx?d=22474 Accessed 22 January 2019.

[3] American Councils on International Education. (2017). The National K-12 Foreign Language Enrollment Survey Report. https://www.americancouncils.org/news/announcements/new-report-world-language-study-us-k-12-schools Accessed 22 January 2019.

[4] Appiah, K. (2006). Cosmopolitanism: Ethics in a World of Strangers. New York: Norton.

[5] Brennan, T. (1997). At Home in the World: Cosmopolitanism Now. Boston: Harvard.

[6] British Council (2013). The English Effect. https://www.britishcouncil.org/organisation/policy-insight-research/research/theenglish-effect Accessed 22 January 2019.

[7] Cialdini, R. (2006). Influence: The Psychology of Persuasion. New York: Harper Business.

[8] Committee for Economic Development. (2006). Education for Global Leadership: The Importance of International Studies and Foreign Language Education for U.S. Economic and National Security. https://www.ced.org/reports/education-for-globalleadership Accessed 22 January 2019.

[9] Devlin, K. (2018). Most European Students are learning a foreign language in school while Americans lag. http://www.pewresearch.org/fact-tank/2018/08/06/most-european-students-are-learning-a-foreign-language-in-school-whileamericans-lag/Access 22 January 2019.

[10] Devlin, K. (2015). Learning a foreign language a must in Europe: Not so in America. http://www.pewresearch.org/facttank/2015/07/13/learning-a-foreign-language-a-must-in-europe-not-so-in-america/ Accessed 22 January 2019.

[11] Dornyei, Z. (1998). Motivation in second and foreign language learning. Language Teaching 31: 3 117-135.

[12] Education Commission of the United States (2007). 50-State Comparison: High School Graduation Requirements. https://www.ecs.org/high-school-graduation-requirements/Accessed 22 January 2019.

[13] Gardner, R. \& Lambert, W. (1972). Attitudes and motivation in second-language learning. Boston: Newbury House.

[14] Gladwell, M. (2000). The Tipping Point: How Little Things Can Make a Big Difference. New York: Little, Brown.

[15] Goldenberg, C. \& Wagner K. (2015). Bilingual Education: Reviving an American Tradition. https://www.aft.org/ae/fall2015/goldenberg_wagner Accessed 22 January 2019.

[16] Grosjean, F. (2018). The Amazing Rise of Bilingualism in the United States. https://www.psychologytoday.com/us/blog/lifebilingual/201809/the-amazing-rise-bilingualism-in-the-united-states Accessed 22 January 2019.

[17] Gunesch, K. (2004). "Education for Cosmopolitanism?: Cosmopolitanism as a Personal Cultural Identity Model for and within International Education.” JRIE: Journal of Research in International Education 3 (3) 251-275.

[18] Gunesch, K. (2013). Intercultural Understanding via Local and Global Educational Citizenship: A Contribution to International Education via a Lived-in Substantiation of multilingualism and cosmopolitanism.” JRIE: Journal of Research in International Education 12(2) 173-189. 
[19] Hoff, E. \& Core, C. (2015). "What Clinicians Need to Know about Bilingual Development." Seminars in Speech and Language $36(2), 89-99$.

[20] Huebener, T. (1961). Why Johnny Should Learn Foreign Languages. Philadelphia, Chilton.

[21] Jaumont, F. (2017). The Bilingual Revolution: The Future of Education in Two Languages. New York: TBR.

[22] Kettelkamp, G. (1940). "A Factor in Presenting Our Product." Modern Language Journal 25(3), 164-167.

[23] Kim, W. \& Mauborgne, R. (2017). Blue Ocean Shift: Proven Steps to Inspire Confidence and Seize New Growth. New York: Hachette.

[24] Kim, W. \& Mauborgne, R. (2015). Blue Ocean Strategy, Expanded Edition: How to Create Uncontested Market Space and Make the Competition Irrelevant. Boston: Harvard Business Review Press

[25] Kotter, J. (2008). A Sense of Urgency. Boston: Harvard Business Press.

[26] Language Flagship (2009). What Business Wants: Language Needs in the 21st Century. https://nsep.gov/sites/default/files/What\%20Business\%20Wants\%20Report.pdf Accessed 22 January 2019.

[27] Lee, N. \& Kotler, P. (2015). Social Marketing: Changing Behaviors for Good, 5th ed. Thousand Oaks, CA: Sage.

[28] Livermore, D. (2016). Driven by Difference: How Great Companies Fuel Innovation through Diversity. New York: AMACOM.

[29] Mackey, Alison. (2014). Wanting It Enough: Why Motivation is the Key to Language Learning. https://www.theguardian.com/education/2014/jun/26/motivation-key-language-learning Accessed 22 January 2019.

[30] Many Languages One World (n.d.) https://www.manylanguagesoneworld.org/Accessed 22 January 2019.

[31] Mazzoni, G. (2018). The 'real you' is a myth - we constantly create false memories to achieve the identity we want https://theconversation.com/the-real-you-is-a-myth-we-constantly-create-false-memories-to-achieve-the-identity-we-want103253 Accessed 22 January 2019.

[32] McComb, C. (2001). About One in Four Americans Can Hold a Conversation in a Second Language. https://news.gallup.com/poll/1825/about-one-four-americans-can-hold-conversation-second-language.aspx Accessed 22 January 2019.

[33] Modern Language Association. (2007). Foreign Languages and Higher Education: New Structures for a Changed World. https://www.mla.org/Resources/Research/Surveys-Reports-and-Other-Documents/Teaching-Enrollments-andPrograms/Foreign-Languages-and-Higher-Education-New-Structures-for-a-Changed-World Accessed 22 January 2019.

[34] Modern Language Association. (2012). The MLA Survey of Postsecondary Entrance and Degree Requirements for Languages Other than English. https://www.mla.org/Resources/Research/Surveys-Reports-and-Other-Documents/Teaching-Enrollmentsand-Programs/The-MLA-Survey-of-Postsecondary-Entrance-and-Degree-Requirements-for-Languages-Other-Than-English2009-10 Accessed 22 January 2019.

[35] NAFSA: Association of International Educators. (2003). Securing America's Future: Global Education for a Global Age. http://www.nafsa.org/Policy_and_Advocacy/Policy_Resources/Policy_Reports/Securing_America_s_Future/Accessed 22 January 2019.

[36] New American Economy (2017). Not Lost in Translation: The Growing Importance of Foreign Language Skills in the US Job Market. https://research.newamericaneconomy.org/report/not-lost-in-translation-the-growing-importance-of-foreign-languageskills-in-the-u-s-job-market/Accessed 22 January 2019.

[37] O'Connell, M. \& Norwood, J. eds. (2007) International Education and Foreign Languages: Keys to Securing America's Future. https://www.nap.edu/catalog/11841/international-education-and-foreign-languages-keys-to-securing-americas-future Accessed 22 January 2019.

[38] Olson, C., Evans, R., \& Shoenberg, R. (2007). At Home in the World: Bridging the Gap between Internationalization and Multicultural Education. Washington, DC: American Council on Education.

[39] Pei, M. (1956). Language for Everybody: What It Is and How to Master It. Philadelphia: Devon-Adair.

[40] Phinney, J. S. (1990). Ethnic identity in adolescents and adults: A review of research. Psychological Bulletin, 108, $499-514$.

[41] Phinney, J. S. \& Ong, A.D. (2007). Conceptualization and measurement of ethnic identity: Current status and future directions. Journal of Counseling Psychology, 54, 271-281.

[42] Ramage, K. (1990). Motivational Factors and Persistence in Foreign Language Study. Language Learning 40:2 189-219.

[43] Ros i Sole, C. (2013). "Cosmopolitan speakers and their cultural cartographies." Language Learning Journal, 41:3 326-339.

[44] Ryan, C. (2013). Language Use in the United States: 2011. https://www.census.gov/library/publications/2013/acs/acs-22.html Accessed 22 January 2019.

[45] Simon, P. (1980). The Tongue-Tied American: Confronting the Foreign Language Crisis. New York: Continuum.

[46] Stearns, P. (2009). Educating Global Citizens in Colleges and Universities: Challenges and Opportunities. New York: Routledge.

[47] Thiery, C. (2018). Louisiana Joins the Francophonie. https://france-amerique.com/en/la-louisiane-rejoint-lafrancophonie/Accessed 22 January 2019.

[48] Tokuhama-Espinosa, T (2008). Multilingualism: Living Languages across the Lifespan. Westport, CT: Praeger.

[49] US Census (2016). Hello my name is. https://www.census.gov/library/visualizations/2016/comm/cb16tps154_surnames_top15.html Accessed 22 January 2019.

[50] United States Government Accountability Office. (2010). Foreign Language Capabilities: Departments of Homeland Security, Defense, and State Could Better Assess Their Needs and Capabilities and Address Shortfalls. https://www.gao.gov/assets/130/125167.pdf Accessed 22 January 2019.

[51] United States Senate. (2012). A National Security Crisis: Foreign Language Capabilities in the Federal Government. https://www.gpo.gov/fdsys/pkg/CHRG-112shrg75214/pdf/CHRG-112shrg75214.pdf Accessed 22 January 2019. 


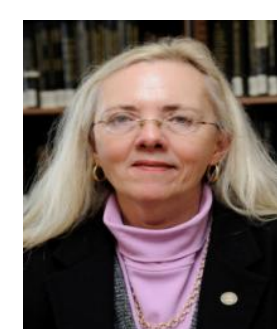

Kathleen Stein-Smith, PhD, Chevalier dans l'Ordre des Palmes académiques, is associate university librarian and adjunct faculty in foreign languages and related areas at Fairleigh Dickinson UniversityMetropolitan Campus, Teaneck, New Jersey.

As a dedicated foreign language educator and advocate, she is Chair of the AATF (American Association of Teachers of French) Commission on Advocacy. She is a member of the ATA (American Translators Association) Education and Pedagogy Committee, the CSCTFL (Central States Conference on the Teaching of Foreign Languages) Advisory Council, the NECTFL (Northeast Conference on the Teaching of Foreign Languages) Advisory Council, and is a SCOLT (Southern Conference on Language Teaching) Sponsor. She has also served as French Language Facilitator at MLOW (Many Languages One World).

She has presented at numerous professional conferences, is the author of four books and numerous articles about the foreign language deficit, has given a TEDx talk, The U.S. Foreign Language Deficit_-"What It Is; Why It Matters; and What We Can Do about It", and maintains a blog, "Language Matters." 